\title{
O ENSINO DE LÍNGUA JAPONESA NAS ESCOLAS COMUNITÁRIAS NO PERÍODO PÓS-GUERRA ${ }^{1}$
}

\section{Leiko Matsubara Morales ${ }^{2}$}

Resumo: O presente artigo tem como objetivo apresentar, numa perspectiva histórica, o ensino de língua japonesa nas escolas comunitárias do Brasil no período pós-guerra, apontando as principais características desse ensino em torno dos descendentes de japoneses.

Palavras-chave: escola comunitária japonesa; língua estrangeira; língua de herança.

Abstract: This article aims to present a historical perspective of the Japanese language education in community schools of Brazil in the postwar period, pointing out the main features of this teaching about the descendants of Japanese.

Key-words: Japanese community school; foreign language; heritage language.

\section{Introdução}

Há diversos registros sobre o ensino de língua japonesa aos descendentes nikkeis no Brasil (NICHIGAKUREN³ ${ }^{3}$ 1966; NOMOTO:1974; ISHIHARA:1978; MORIWAKI:1989;1999, entre outros). Nichigakuren (1966) recupera artigos norteadores do ensino de língua japonesa que retratam o clima da época do período pós-guerra, marcado ainda por dúvidas e incertezas quanto à reabertura das escolas comunitárias japonesas. Ishihara (1978) narra a história da escola japonesa de Cotia ao longo de cinquenta anos, começando como escola comunitária, a seguir sendo reconhecida pelo governo e, finalmente, tornando-se uma escola pública.

1. Este artigo é uma versão resumida de um dos capítulos da tese de doutorado intitulada Cem anos de imigração japonesa no Brasil: o japonês como lingua estrangeira (2009).

2. Docente do Curso de Língua e Literatura Japonesa do Departamento de Letras Orientais da Faculdade de Filosofia, Letras e Ciências Sociais da Universidade de São Paulo.

3. Abreviação de Hakkoku Nihongo Gakkô Rengôkai - Federação das Escolas de Língua Japonesa do Brasil. 
Com base nos dados coletados por esse autor, podemos vislumbrar um espaço de coexistência entre os sistemas educacionais japonês e brasileiro. Moriwaki (1998; 1999) faz um estudo cronológico da evolução das concepções de ensino de língua japonesa no Brasil ${ }^{4}$. Há ainda outros trabalhos que enfatizaram os aspectos linguísticos da comunidade nipo-brasileira (NOMOTO:1974; DOI:2000; 2002;2006; 2007; TAKANO:2002; KUYAMA: 1999;2000; KUNO: 2007; MORALES:2009; entre outros), trazendo à tona a variação linguística do japonês falado no Brasil. $\mathrm{O}$ interesse da autora pela história do ensino-aprendizagem de língua japonesa surgiu da necessidade de compreender o contexto do cotidiano escolar no âmbito da escola comunitária, no período que vai do pós-guerra até a década de 1980 .

\section{Contexto Social do Período Pós-Guerra}

Com a ruptura do processo migratório entre os anos de 1941 e 1952, pouco mais de dez anos separaram os imigrantes japoneses do pré e do pós-guerra, deixando marcas indeléveis na comunidade. Como salienta Moriwaki $(1998 ; 1999)$, uma das transformações mais significativas no campo educacional foi a mudança de concepção do ensino da língua japonesa, antes focada na formação de japoneses visando retorno ao país natal, com ensino de língua japonesa na perspectiva de língua materna, passando a ser um ensino voltado para a transmissão dos costumes e valores japoneses, com decisão de permanência no Brasil, conhecida como língua de herança (LH). As escolas comunitárias de japoneses - os nihongogakkô - passaram a seguir uma nova ordem instalada no país, impulsionada pela queda do regime de Getúlio Vargas em 1946 e a promulgação da nova Constituição, após um longo período ditatorial.

Na comunidade japonesa a partir de 1952, a entrada de novos imigrantes bem como a volta da circulação de jornais escritos na língua japonesa ${ }^{5}$ proporcionou renovação linguística e cultural. Há, ainda, outros fatores que valorizaram o uso da língua japonesa como a entrada de empresas japonesas no Brasil, principalmente entre os anos de 1957 e 1962, alimentando uma nova perspectiva de emprego para os descendentes falantes daquele idioma ${ }^{6}$

Com a vinda de 190.000 japoneses nativos no período pré-guerra, mais 53.555 novos japoneses, entre 1952 e 19887 , nos estados de São Paulo e Paraná,

4. A autoria dos trabalhos levantados são de pessoas que se engajaram no ensino de língua japonesa (diretores e professores). Trata-se de uma visão baseada em experiências empiricas de sujeitos que participaram no processo de ensino-aprendizagem de língua japonesa, e são membros da comunidade Nikkei.

5. Com a nova Constituição, o jornal São Paulo Shinbun volta a circular em 12 de outubro de 1946; o jornal Nanbei Jiji em 23 de dezembro de 1946, e o jornal Paulista Shinbun em $1^{\circ}$ de janeiro de 1947.

6. No rol de empresas que vieram estão Usiminas, Toyota, Ajinomoto, Ishikawa-jima, entre outras.

7. Wakisaka et alii (org.) Uma epopéia moderna - 80 anos de imigração japonesa do Brasil. Editora Hucitec, 1992. 
havia uma quantidade significativa de comunidades japonesas espalhadas nesses estados, principalmente em São Paulo. No período pré-guerra, os imigrantes eram em sua maioria agricultores; no pós-guerra houve a entrada de jovens (Cotia-seinen", hanayome imin", imigrantes industriais, entre outros), injetando "novo ânimo nas comunidades receptoras", Wakisaka et alii (1992). Ainda no pós-guerra formaram-se novos núcleos de imigrantes, em Colônia Funchal (RJ), Colônia Guatapará (SP) e Colônia Jacareí (SP), Colônia Pinhal (SP), Colônia Kyoei (MS) ${ }^{10}$, caracterizados por forte domínio da língua japonesa, assim como a entrada de recém-chegados em comunidades pré-existentes ajudou na revitalização linguística.

Esse encontro dos japoneses novos com os antigos tem sido marcado por percepção de estranhamento nos hábitos culturais e linguísticos de ambos os lados. Handa (1970:715) dedica algumas páginas no seu livro com referência aos "Japão-novo" - os imigrantes do pós-guerra - e aos "Burajiru-boke" - imigrantes que incorporaram hábitos brasileiros, dado o modo diferente de como os últimos interpretavam as situações do cotidiano em relação à noção de tempo, por exemplo. Além da diferença na formação intelectual e valorativa de novos imigrantes, os antigos não compreendiam conceitos a respeito de "democracia" e "igualdade", implantados no Japão do pós-guerra (FONTENELE REIS: 2002)

As comunidades japonesas do interior do estado de São Paulo, por exemplo, continuavam a valorizar descendentes monolíngues em Japonês que preservaram valores herdados dos pais, com características mais nipônicas do que brasileiras, enquanto que na cidade de São Paulo, a integração dos descendentes à sociedade brasileira já era maior. No pós-guerra, a decisão de permanecer no Brasil decorreu do fato de que muitos já gozavam de boa condição financeira alcançada, direcionando a atenção para a educação brasileira de seus descendentes. Havia assim, uma considerável distância entre a educação de jovens que permaneciam na zona rural e daqueles que prosseguiam seus estudos na capital, segundo Handa (1970), Wakisaka et alii (1996), entre outros.

8. De acordo com Wakisaka et alii (1992) houve dois tipos de imigração: a planejada e a livre. Aqui destacaremos a planejada: após a entrada em vigor do Tratado de Paz de 1952, a Cooperativa Agrícola de Cotia (CAC), em parceria com a Cooperativa Central das Cooperativas Agrícolas do Japão (Nôkyô) e com autorização do governo brasileiro, trouxe jovens lavradores para serem recebidos por associados/cooperados da CAC, na forma de "chamada de parentes". Assim, vieram cerca de 1.500 jovens, denominados "jovens imigrantes de Cotia" (Cotia Seinen), entre os anos de 1955 a 1958. Embora numericamente reduzido, há os imigrantes industriais, conhecidos como Sangyô Kaihatsu Seinentai (Grupo de Jovens para o desenvolvimento industrial), além desses, houve duas grandes levas de imigrantes, cuja iniciativa partiu dos japoneses residentes no Brasil, conhecidos como Tsuji e Matsubara, que conseguiram trazer, respectivamente, 5.000 e 4.000 famílias de japoneses, levando-os para colonizar as regiões Amazônica, Centro-oeste e Nordeste do país.

9. Imigrantes japonesas que vieram para o Brasil com o propósito de contrair matrimônio com os imigrantes japoneses de pós-guerra.

10. Comissão de Elaboração do $50^{\circ}$. da imigração pós-guerra. Imigração Japonesa no Brasil - Meio Século após II Guerra Mundial (1953-2003), Associação dos Imigrantes Brasil-Japão, 2004. 
A diferença linguística do japonês falado na comunidade não passou despercebida aos ouvidos dos novos imigrantes ${ }^{11}$. que se surpreenderam com a realidade do ensino tão distante daquela com a qual estavam acostumados no Japão, como também estranharam o falar dos japoneses locais, que não se parecia com nenhum dialeto japonês, mas era misturado ao português, com frequentes empréstimos. Escolas que usavam livros didáticos do pré-guerra também não eram incomuns, dado o estoque de material que aqui havia permanecido; como também não houve por durante muito tempo a importação de livros didáticos e a manutenção da versão antiga por convicção ideológica; nessa época, para não correr riscos de confisco os livros didáticos eram comercializados como os de literatura nas livrarias japonesas do bairro da Liberdade. No Japão, a nova versão da série didática supervisionada por Yanagida Kunio já estava em circulação, sendo que o mesmo não acontecia no Brasil.

\section{A Retomada das Escolas Comunitárias Japonesas}

Pequenos grupos de professores começaram a retomar suas atividades em 1947. Reuniões voltaram a acontecer no distrito de Santo Amaro e em alguns pensionatos de japoneses existentes nas cidades do interior, como Presidente Prudente. E em torno do objetivo de retomar o funcionamento das escolas comunitárias, professores e japoneses nativos se reuniram formando a Nichigakuren (Hakkoku Nihongo Gakkô Rengôkai - Federação das Escolas de Língua Japonesa do Brasil) ${ }^{12}$. A oficialização da escola comunitária foi por meio de encaminhamento de ofícios junto às autoridades brasileiras locais e, assim, obter autorização para sua reabertura $^{13}$ Nem sempre aqueles que tinham atuado com ímpeto na fase pré-guerra voltaram ao cenário educacional no pós-guerra pois muitos tinham perdido seus postos de trabalho, alguns haviam deixado o Brasil e retornado ao Japão, outros, ainda, mantiveram conviç̧ões e, mesmo na clandestinidade durante a vigência da Segunda Guerra Mundial, continuaram ensinando a "língua proibida" em áreas recônditas ou em forma de aula itinerante.

11. Segundo o relato de duas professoras octogenárias, que tiveram suas vidas interceptadas pela guerra, as duas passaram por experiências muito semelhantes. Elas eram filhas de imigrantes já bem posicionados na comunidade japonesa do Brasil, e por conta disso, na eminência da guerra, os pais tinham decidido enviar parte da família antes, como a mãe e as filhas ao Japão, permanecendo o pai e os filhos no Brasil, para depois se encontrarem. No entanto, devido às proporções tomadas pela eclosão da guerra e por conta da suspensão das relações diplomáticas entre os dois países, a família ficou separada por mais de uma década. Uma concluiu o magistério e, a outra, a faculdade de pedagogia, mas assim que a situação normalizou-se, em 1952, voltaram ao Brasil. Apesar de cada uma ter trilhado um caminho diferente, começaram a trabalhar como professoras de japonês e continuam exercendo sua profissão.

12. Jûnenshi. (História dos dez anos de fundação da Federação das Escolas de Língua Japonesa do Brasil).

13. As próprias denominações de associações japonesas sofreram mudanças, passando geralmente para Associação Cultural e Esportiva Nipo-Brasileira (de tal cidade). 
O trecho abaixo é um testemunho de um jun nissei ${ }^{14}$ sobre o estado psicológico dos japoneses isseis:

\begin{abstract}
"A gente que era mais jovem começou a agitar com os pais das crianças se não era possível retomar e unificar os nihongogakkô [escolas japonesas] espalhados pela vila, voltar a ser o que era antes, com uma escola comunitária unificada na sede do clube, onde todos se reuniam. Quando a escola estava cheia, chegava a juntar uns 150 alunos. Mas, os pais dos alunos estavam reticentes, não conseguiam captar o clima do momento. A situação já não estava tão pesada e era uma ocasião favorável para retomar as escolas. Eu mesmo tinha conversado com o delegado da nossa seção sobre o funcionamento das escolas e ele tinha me acenado com uma resposta evasiva: "não estou sabendo de nada" e interpretei isso como um sinal verde. Ele estendeu as mãos e nós nos despedimos. Para mim, a gente poderia voltar sem receio, não poderia haver perseguição e nem perigo de denúncia, mas não sei se era por causa da língua que eles (os japoneses) não entendiam, mas a gente que era jovem, a gente já tinha percebido que não havia mais risco, ainda assim, nós do Seinenkai não conseguíamos convencer os pais a enviar seus filhos aos nihongogakkô". Eles pareciam estar muito desanimados, pareciam apáticos." ${ }^{\prime 15}$
\end{abstract}

Transcorrida cerca de uma década após o fim da guerra, a liderança comunitária já não estava totalmente nas mãos de isseis, mas também de descendentes e de jun nisseis. Esses jovens falavam português, entendiam a cultura brasileira, os valores e a visão de mundo da terra-hospedeira, conseguindo um trânsito melhor nas duas culturas.

Ainda sob os efeitos da proibição de ensino da língua japonesa ${ }^{16}$, como também das marcas deixadas pelo caos que havia se instalado na colônia por conta do movimento Shindôren 'mei ${ }^{17}$, pairava no ar um clima de pessimismo e de desesperança nas comunidades japonesas.

14. Termo usado para se referir a filhos de imigrantes que para cá vieram antes de completar o ensino primário, ou seja, até completar 12 anos de idade.

15. Relato de informante de 81 anos, residente de Suzano, São Paulo. Entrevista realizada em junho de 2007.

16. O Decreto-lei n. 406 , de 4 de maio de 1938, regulando a entrada e permanência de estrangeiros no território nacional, estabelecia que "em todas as escolas rurais do país" o ensino de todas as matérias deveria ser ministrado em português (art. 85, caput); o mesmo artigo determinava que essas escolas deveriam ser dirigidas necessariamente por "brasileiros natos" $\left(\S 1^{\circ}\right)$, sendo nelas proibido o ensino de idiomas estrangeiros a menores de quatorze anos $\left(\S 2^{\circ}\right)$, e todos os livros destinados aos cursos primário deveriam ser escritos exclusivamente em português $\left(\S 3^{\circ}\right)$. Além disso, outras sérias restrições eram previstas: a publicação de livros, revistas ou jornais em língua estrangeira "nas zonas rurais" ficava condicionada à permissão do Conselho de Imigração e Colonização (art. 86); a publicação de qualquer material em língua estrangeira (incluindo livros, folhetos, revistas, jornais e boletins) ficava sujeita “à autorização e registro prévio no Ministério da Justiça" (art. 87), sendo ainda vedada denominação em idioma estrangeiro a qualquer núcleo colonial, centro agrícola, estabelecimento ou associação (art. 42). Fonte: base de dados da legislação brasileira, Senado Federal (www.senado.gov.br).

17. Literalmente "Aliança dos Súditos"; o grupo espalhou boatos de que o Japão havia vencido a Segunda Guerra Mundial, tendo conseguido, em poucos meses, formar uma organização com vinte mil famílias e 100.000 inte- 
A atuação de descendentes e de jun'nissei foi decisiva já que por esses serem conhecedores da cultura brasileira e da língua portuguesa, conseguiam captar o clima de opinião da época, como também conhecer o funcionamento das leis brasileiras; já que, não obstante a vigência do decreto-lei de proibição de ensino de línguas estrangeiras, havia brechas e formas de contornar situações recorrendo a autoridades locais. (cf. Associação Cultural Nipo-Brasileira de Araçatuba:1978)18

Circulavam também nos principais jornais da comunidade discursos sobre a necessidade do ensino de japonês para descendentes ${ }^{19}$ e em 1949, instaurou-se uma Comissão Nacional de Educação (Zenpaku Kyôiku Kyôgikai). Até haver o estabelecimento efetivo da Confederação Brasileira das Escolas Reconhecidas pelo Governo Brasileiro (Hakkoku Kônin Nichigo Gakkô Rengôkai), foram realizadas diversas reuniões, mas segundo Nichigakuren, o mais importante foi a da Primeira Reunião das Escolas Primárias de Língua Japonesa do Estado de São Paulo reconhecidas pelo governo brasileiro (Daikkai Sanpauroshû Kônin Nichigoshôgakkô Renrakukaigi) ocorrida em 25 de julho de 1954, na Escola Japonesa Pedro II, no qual houve indicação do desejo de retomar o ensino de língua japonesa no período pós-guerra, agora liderada pela iniciativa local ${ }^{20}$ (NICHIGAKUREN, 1966:115).

Sobre o conteúdo da reunião, os registros mostram que se discutiu a metodologia de ensino, questões que envolviam salários de professores, estudos prospectivos sobre o decreto-lei de proibição de ensino da língua japonesa, instalação de um corpo institucional, obrigatoriedade de ensino reconhecido pelas leis brasileiras, realização de eventos escolares, elaboração e edição de livros de leitura para crianças, entre outros assuntos (NICHIGAKUREN, 1984:35).

No ano seguinte, em 1955, uma nova reunião foi organizada com 25 professores e 36 mantenedores de escolas japonesas; no entanto, não havia ainda uma diretriz sobre o ensino de língua japonesa. Consta no boletim da Nichigakuren que os líderes da época, aproveitando-se da visita do secretário do Ministério da Educação e das Relações Exteriores do Japão ao Brasil, em fevereiro de 1955, solicitaram uma reunião, na qual discutiram-se temas como: "novo sistema escolar do Japão do pós-guerra, a filosofia de ensino, os livros didáticos, o conteúdo programático do ensino no primário japonês, o currículo das escolas primárias da

grantes que acreditavam na vitória japonesa, aproveitando-se da situação de que não havia jornais ou nenhum outro veículo de informação em língua japonesa circulando na ocasião. Espalharam boatos, forjaram fotos e criaram situações para que se acreditasse na versão da vitória japonesa. Assim, aqueles que acreditavam na vitória japonesa eram considerados os kachigumi, ou seja, "vitoristas" e aqueles que sabiam da realidade, os makegumi ou "derrotistas", sendo estes últimos acusados de traidores por reconhecer a verdade.

18. Boletim Comemorativo dos cinquenta anos da fundação da Associação Cultural Nipo-brasileira de Araçatuba.

19. Os jornais japoneses da Colônia, São Paulo Shinbun, Paulista Shinbun, Nippaku Mainichi Shinbun assim como as revistas de formadores de opinião como Koronia, Jidai, entre outros.

20. Inicialmente, no período pré-guerra havia uma organização conhecida como Associação de Difusão do Ensino de Língua Japonesa (Bunkyô Fukyûkai) sob a supervisão do Consulado Geral do Japão. 
época", na qual (reunião) obtiveram um parâmetro de como era a tendência da educação do Japão no pós-guerra. A Nichigakuren também consultou o diretor da Tamagawa Gakuen ${ }^{21}$, Obara Kunio, de quem recebeu orientações sobre os fundamentos educacionais (em 24 de julho de 1955). Nesse mesmo ano, tinha início a $1^{\text {a }}$ organização do Concurso Nacional de Oratória Infantil ${ }^{22}$, realizado na Escola D. Pedro II, em decorrência da orientação que recebera na ocasião.

Não obstante ao fato de haver menção sobre o ensino da língua na perspectiva de língua estrangeira (LE) ${ }^{23}$, do ponto de vista prático, parece não ter havido ruptura de modelos antigos japoneses. O que houve, na verdade, foi a introdução da concepção vigente da educação japonesa no pós-guerra, diferente na sua essência do pré-guerra, e foi amplamente incorporado como um modelo de ensino da época:

As escolas japonesas no Brasil mantiveram as práticas que reuniam a família toda, tais como a celebração de cerimônias de abertura e encerramento de aulas e cursos, concurso de oratória, apresentação de atividades artísticas, gincana poliesportiva (Undôkai) etc. Para a sua caracterização, as escolas tinham seu hino escolar próprio ( $k o \hat{k} k a)$, com a letra composta por pais e/ou professores ou por músicos ilustres do Japão, que fazia frequentemente referência aos aspectos locais de onde estava a escola. Além disso, cantavam os dois hinos nacionais várias cerimônias: brasileiro e japonês - o kimigayo. Também não faltava a música de despedida hotaru no hikari (o brilho do vaga-lume), em cerimônias de formatura.

As escolas comunitárias começavam as atividades do dia com uma ginástica matinal, conhecida como rajio taisô, antes de se dirigirem às salas de aulas. E depois que entravam, antes de se sentar, invariavelmente, todos declamavam em voz alta: kiritsu-rei-chakuseki (levante-se, cumprimente-se e sente-se), cujas palavras eram, passo a passo, acompanhadas por gestos de reverência. Às vezes, intercalava-se o $k i$-o-tsuke (atenção!) numa sucessão de movimentos. Depois eram feitas as chamadas para anotar a presença ou a ausência, escrevia-se na vertical a data no canto da lousa, seguida das condições do tempo, se o dia estava ensolarado ou chuvoso.

21. Tamagawa foi formada em 1929, como escola de ensino primário. Depois, ela se expandiu para escola de ensino médio e, em 1947, por ser uma instituição pré-guerra e estar configurada no sistema antigo de educação, foi reconhecida como universidade. Seus preceitos educacionais se baseiam no Zenjinkyôiku "educação integral do ser humano" que incorpora cultura humana em harmonia com a personalidade, respeito à individualidade, autonomia na aprendizagem e busca a integração da "verdade", "bondade", "beleza", "santidade", "saúde" e "riqueza", de acordo com o site da faculdade, acessado em 25.06.2008.

22. Participaram as escolas comunitárias da capital, das Linhas Central, das imediações da cidade de São Paulo, Região Leste, Oeste, Sul e Norte, somando 145 participações de crianças.

23. O conceito de língua estrangeira refere-se àquela que é aprendida pelo aluno em situação de sala de aula. Muitas vezes, o estudo se limita à gramática e à conversação funcional em sala de aula, e o aluno não está no país em que se fala essa língua. A língua não é o meio de comunicação direta no seu dia a dia, sendo os insumos linguístico controlados por ser em ambiente de sala de aula. 


\title{
4. Os Efeitos da Cisão entre "Vitorista" e "Derrotista" no Ensino de Língua Japonesa
}

\author{
A Segunda Guerra provocou impacto na vida de muitos japoneses. Segundo \\ Jin'nai $(1981: 229)^{24}$

\begin{abstract}
“os japoneses do pré-guerra, mesmo vivendo no Brasil enxergavam a longínqua terra natal como um refugio psicológico. Diferentemente do dia de hoje, eles não entendiam bem a língua brasileira, tinham forte sentimento de estar trabalhando em caráter provisório no Brasil e por estarem mentalmente ligados à terra natal, muitos acreditavam piamente nas notícias gloriosas de vitória do Japão". (Tradução nossa).
\end{abstract}

Neste contexto, o grupo Shindôren'mei conseguiu disseminar boatos, cometendo extorsão, estelionatos e até assassinatos contra patrícios, aproveitando-se da situação peculiar em que as pessoas viviam isoladas no campo e a falta de esclarecimento sobre o assunto, instaurando, com isso, uma situação de caos na comunidade nipo-brasileira. O fato é conhecido da comunidade pelos imigrantes que viveram essa época e foi divulgado em diversos livros editados na Colônia ${ }^{25}$, uma vez que a maioria dos relatos vem da ala "derrotista", considerada "mais informada e consciente dos fatos reais", em contraste à ausência de registros dos "vitoristas" Diversos jornais e revistas noticiaram o fato, não só na comunidade como também fora dela, inclusive pela imprensa brasileira não-nikkei ${ }^{26}$ Jin nai (op.cit.) conta que os pais "vitoristas" não permitiam que seus filhos brincassem com os filhos dos "derrotistas", famílias cujos pais fossem de opiniões diferentes se rompiam por diferenças ideológicas, casamentos eram cancelados etc.

Moriwaki (1998:45) relatou casos de pais que se recusaram a deixar os filhos na Escola Primária de Cotia, por essa adotar novos livros didáticos do Japão editados no pós-guerra, no qual havia menção explícita à derrota japonesa. Os pais não aceitavam que o Japão havia sido derrotado na guerra. Era tamanha a exacerbação dos ânimos em relação a esse assunto que alguns chegavam a abrir novas escolas de língua japonesa com membros que tinham a mesma posição.

Segundo informante $\mathrm{B}^{27}$, na cidade de Álvares Machado, interior do estado de São Paulo, houve cisão entre os moradores na seção 6, no núcleo conhecido

24. História dos 70 anos de imigração japonesa no Brasil. 1981

25. Neste trabalho empregaremos o termo "colônia" para designar toda a população de japoneses e seus descendentes residentes no país. Como contraponto, empregaremos o termo comunidade para designar um grupo de um lugar especifico. Assim, a Colônia Japonesa indica a totalidade dos japoneses residentes no Brasil e a comunidade será dirigida para um lugar específico, ou seja, como a comunidade de japoneses de Suzano, de Santos ou de outro lugar.

26. Fernando Morais escreve vários relatos em Corações Sujos, 2004.

27. Relato de informante de 78 anos, nissei, residente em Álvares Machado. Entrevista realizada em junho de 2008. 
como Hakkô-shokuminchi (Colônia Hakkô), que contava com cerca de 40 famílias, mas se dividiu em "vitoristas" (20 famílias) e em "derrotistas" De acordo com ele, a escola comunitária da seção, que contava com apenas 35 alunos, ficou reduzida a 20. As atividades esportivas ficaram também separadas: os "vitoristas", com atletismo e beisebol e, os "derrotistas", com judô. A escola veio encerrar suas atividades na década de 1970, por causa do êxodo rural. Hoje restam apenas 8 famílias nessa seção.

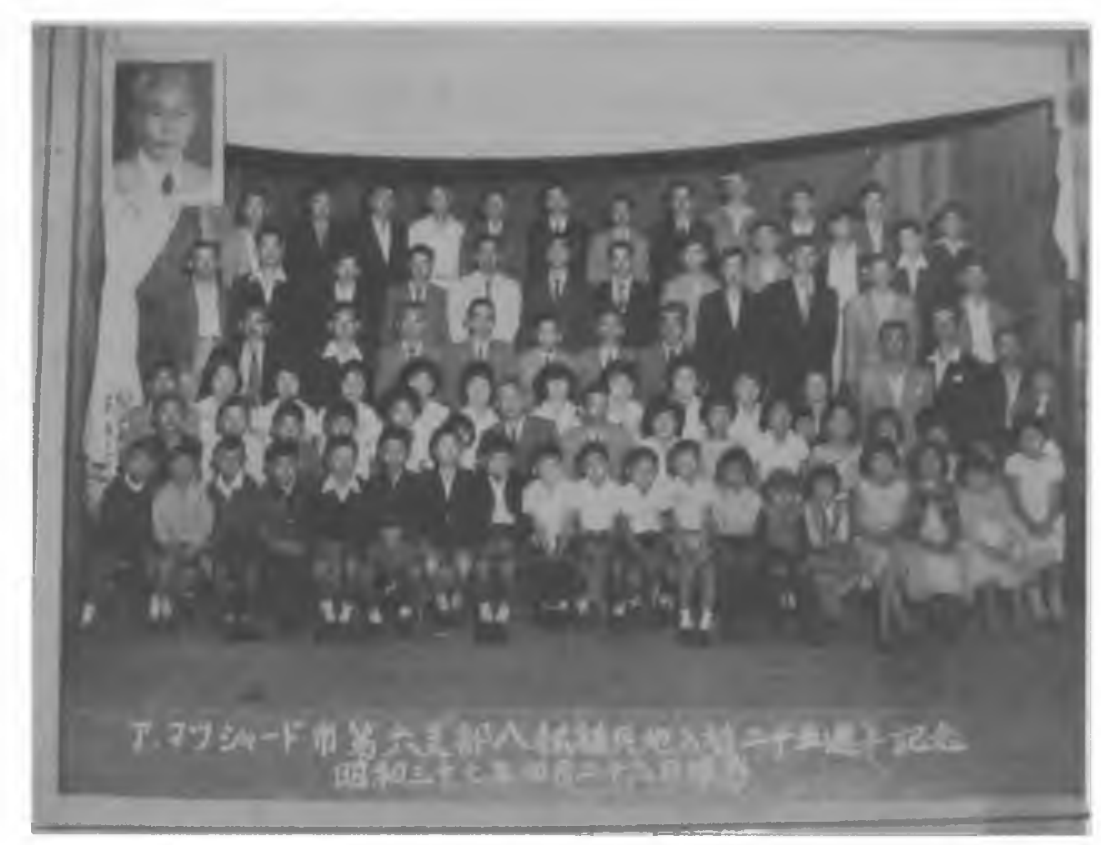

$25^{\circ}$. Aniversário da fundação da Colônia Hakkô. $6^{\mathrm{a}}$. seção - Álvares Machado, São Paulo Alunos e pais de alunos, 29 de abril de 1962. Arquivo pessoal: Sr. Kiichi Maeda

Em maior ou menor grau, esse mal estar repercutiu na comunidade japonesa como um todo, e atingiu também os professores e alunos de japonês. Os professores que trabalhavam para as associações de japoneses, cujos presidentes se consideravam "vitoristas", tinham de manter a postura afinada com eles caso não quisessem perder o emprego. Além disso, as crianças de pais "derrotistas" sofriam perseguição de outras crianças.

Moriwaki (op.cit.:68) registra que essa cisão entre "vitoristas" e "derrotistas" trouxe consequências danosas ao ensino de japonês, chegando a expulsar os "derrotistas" que eram minoria das associações e, com isso, crianças deixaram de estudar o japonês. Alguns informantes relataram que quanto maior o sentimento nacionalista e "vitorista" do patriarca da família, seus filhos apresentavam melhores rendimentos no estudo da língua japonesa. Segundo eles, notava-se também a incorporação de condutas e atitude tipicamente de japoneses, como a linguagem não verbal, formas de reverenciar, as respostas afirmativas em uníssono "hai" [sim, senhor(a)], que destoavam da forma brasileira de responder mais branda. Enquanto isso os "derrotistas" comportavam-se como brasileiros e quase não fa- 
lavam em japonês ${ }^{28}$. Esses relatos só vêm a confirmar como o domínio da língua, nessa época, esteve atrelado à postura ideológica dos pais.

Nos períodos de 1960 a 1980, dois movimentos começam a divergir no campo educacional: uma foi a aceleração do ingresso dos nisseis no ginásio e nos cursos de níveis superiores, com a mobilidade dos japoneses rumo à capital de São Paulo. (SAITO:1980). Cardoso (1998:135) analisa o processo de chegada dos japoneses à cidade e assinala que a indicação de amigos e parentes constituiu o meio mais usado pelos japoneses para sua instalação na capital. Outro fato, que parece ir diametralmente no lado oposto é a volta do funcionamento das escolas comunitárias a partir de $1950^{29}$, passando a desempenhar um importante papel na formação cultural e linguística dos descendentes.

Segundo informante $C^{30}$, ele mesmo deixou a região Noroeste em 1960, vendendo as terras que eram destinadas a plantações de café, para trabalhar com alguma atividade em São Paulo, ainda incerta na época, vindo para capital por causa de sua saúde frágil e para dar educação aos filhos. Por meio da indicação de amigos mudou-se para Vila Jacuí, atual bairro da zona leste de São Paulo, na época em que havia lavoura de hortaliças espalhadas na colina da região; reencontrou vários de seus vizinhos, ex-moradores da cidade do interior. Trabalhou como professor de japonês a convite da associação de japoneses do bairro, hoje conhecida como Associação Três Coroas, que no auge, na década de 1970, chegou a ter mais de 170 descendentes como alunos.

Dessa forma, a maneira como os japoneses se agregavam no interior também se repetia na capital, e formaram-se novas associações, como aconteceu em diversas comunidades da zona leste de São Paulo.

Do ponto de vista interno da comunidade, as mudanças significativas foram: a prosperidade econômica alcançada pelos imigrantes que já estavam instalados desde o pré-guerra e a inserção cada vez maior de descendentes nas escolas brasileiras, buscando ingresso nos cursos superiores ${ }^{31}$

28. Relato de informante de 80 anos, jun 'nissei, residente de Suzano, São Paulo. Entrevista realizada em junho de 2005.

29. A medida de abrandamento contra o funcionamento das escolas comunitárias de estrangeiros teria sido publicada em 26 de novembro de 1947, segundo a Associação de Pesquisa Educacional de Londrina (1962). No entanto, devido ao clima da época e das condições psicológicas das comunidades, não havia ainda um movimento para estudar as possibilidades de retorno das escolas comunitárias.

30. Relato de informante de 93 anos, japonês issei, residente da zona leste da cidade de São Paulo.

31. Segundo Wakisaka et alii (op.cit.), ainda na década de 1950 e 1960 não era grande o número de estudantes Nikkeis nos cursos universitários, como também a escolha de carreira refletia muito a situação de ascensão social dos japoneses que escolhiam profissões promissoras financeiramente, nas áreas de direito, medicina, contabilidade, agronomia, por exemplo. Somente, a partir de 1970, haverá uma diversificação na escolha dos cursos, aparecendo cursos de línguas, letras, psicologia, geografia, biologia, entre outros. Já em 1982, dos 7.788 estudantes que se matricularam na Universidade de São Paulo, 978 (13\%) eram nikkeis, revelando alto índice de aprovação e comprometimento com os estudos. 
A partir de 1956, começaram a oferta de bolsas de estudo no Japão pelo Governo Japonês (Monbushô); de 1960 em diante, as bolsas das províncias - os conhecidos kenpiryûgakusei - e os estágios do Ministério das Relações Exteriores; e em 1964 ${ }^{32}$ começaram as das indústrias. Até hoje a maioria das províncias mantêm esse sistema de concessão de bolsas de estudo aos descendentes de seus expatriados. $O$ fato merece menção devido ao contato que estes bolsistas tiveram com a variedade padrão e seus reflexos no retorno à comunidade, seja como falantes, seja como professores de língua japonesa.

\section{As Atividades da Nichigakuren (Federação das Escolas de Língua Japonesa do Brasil)}

Nichigakuren foi responsável por uma série de atividades das escolas comunitárias; em 1957, promoveu a Mostra de trabalhos de alunos de escolas comunitárias do Brasil (Zenpaku Jidô Sakuhin Happyôkai) ${ }^{33}$, na sede do Jornal Paulista, e também a $1^{a}$ Apresentação de Música e Dança Tradicional Japonesa (Zenpaku Jidô Ongaku Buyô Happôkai) ${ }^{34}$, o que marcou época com ensino de valorização humanística, cuja inspiração vinha dos modelos escolares desenvolvidos no Japão, além de reforçar as redes de contato com as escolas comunitárias de outras regiões (NICHIGAKUREN: 1981).

Em 1958, Nichigakuren também organizou o $1^{\circ}$ Seminário Nacional de Professores de Língua Japonesa em São Paulo (Zenpaku Nichigo Kyôshokuin Kôshûkai), com vasta programação de sete dias de duração, seis horas diárias com palestras, no qual participaram 68 professores. Os palestrantes eram figuras proeminentes da comunidade japonesa, como os professores Dr. Hiroshi Saito (Sociologia), Satô Tsunezô (História) e Onodera Shichirô (Música), (NICHIGAKUREN: 1966: 200).

Inicialmente, os seminários eram realizados de forma modesta, em salas emprestadas do Templo Budista Nishihonganji ou na Associação da Província de Osaka "Naniwakai", até encontrar um lugar destinado especialmente ao seminário. No auge desses eventos, na década de 1980, inscreveram-se cerca de trezentos professores e os seminários passaram a ser realizados no auditório da Sociedade Brasileira de Cultura Japonesa (Bunkyô).

32. Comissão da História dos 70 anos de imigração japonesa no Brasil (1981:140).

33. A Mostra contou com a participação de 58 escolas que apresentaram pinturas, caligrafia japonesa, trabalhos manuais, redação, poemas e até redação em português, chegando a reunir um total de 2.800 participações.

34. A apresentação foi realizada no Teatro Colombo, com 180 participantes das escolas da capital paulista e da região de Mogi das Cruzes. 
Como entidade norteadora das escolas japonesas, a Nichigakuren empenhou seus esforços nas atividades de formação humanística conhecidas como jôsôkyôi$k u$ (educação que valoriza a formação humanística) ou ningenzukuri no kyôiku (educação que visa à formação do ser humano) ${ }^{35}$, por meio de aulas que enfatizam arte, música ${ }^{36}$, desenho, pintura e danças tradicionais japonesas. Esses dois termos aparecem com frequência nos registros de Nichigakuren e se referem às atividades pouco desenvolvidas nas escolas públicas brasileiras da época.

Ressalta-se o fato de não haver quase uma descrição dos métodos sobre 0 ensino de língua propriamente dito, provavelmente por não haver necessidade de explicitá-los já que a maioria dos professores era japonês e dos alunos descendente e dominava a modalidade oral da língua.

Entre as décadas de 1960 a 1980 , as escolas japonesas estavam filiadas ao Nichigakuren, dada a força organizacional nos eventos escolares, assim como da apresentação de resultados de trabalhos anuais dos professores de Nihongogakko $\hat{o}^{37}$, legitimando todo o empenho de tais mestres em prol do ensino de língua japonesa. A entidade organizava os principais eventos: Ohanashi Taikai (concurso de oratória, a partir de 1955), Chikaradameshi (concurso de escrita (caligrafia) a partir de 1976) $)^{38}$, e também a Caravana de Confraternização entre estudantes do Brasil e do Japão (Shônen Shôjo Kôkan Shinzen Shisetsudan, a partir de 1980) ${ }^{39}$, exposição de desenhos, organização de seminários, que tinham apoio do Consulado Geral do Japão em São Paulo e da Sociedade Brasileira de Cultura Japonesa.

35. Em Nazaré Paulista, uma cidadezinha próxima a Atibaia, São Paulo, por exemplo, a professora KK, imigrante do pós-guerra, investiu muito nessa filosofia de ensino, por ser a informante formada no magistério e ter atuado no Japão como professora, trazendo a bagagem cultural escolar do Japão, de valorização das artes, da educação musical, como também das danças escolares. O fato de haver uma pessoa formada e com conhecimento da realidade escolar japonesa parece ter influído muito na sinergia das comunidades ao seu redor, não só estimulando os outros professores, como também mobilizando os pais para atividades culturais da cidade, assim como o acompanhamento de crianças de idades inferiores, uma vez que ela incentivava a educação precoce como uma forma de estimular o desenvolvimento intelectual das crianças.

36. Na década de 1980 , muitas escolas do interior adquiriram pianos para as aulas e recebiam periodicamente de São Paulo professores especializados em aula de canto e música.

37. Conferem-se as realizações dessas atividades nas pautas a serem discutidas nas reuniões regionais, principalmente nas escolas do interior do Estado de São Paulo, nas regiões das antigas linhas ferroviárias Noroeste, Sorocabana e Alta Paulista e nas proximidades de Presidente Prudente, bem como no Cinturão Verde (Suzano e Mogi das Cruzes), na região do ABC, nas zonas Leste e Norte e em Santo Amaro.

38. Para se ter noção da amplitude desses eventos, segundo registro da FELJB (1984), o $5^{\circ}$ Concurso de caligrafia (Chikaradameshi Taikai), realizado em março de 1980, obteve a participação de 907 alunos da capital de São Paulo e de onze escolas regionais da Grande São Paulo. A $13^{a}$. edição do Concurso de Oratória (Ohanashi Taikai) foi realizado em 13 de julho de 1980 e contou com a participação de 160 alunos.

39. No primeiro relatório, constam as palavras de congratulações do prefeito Reynaldo Egídio de Barros pela intensificação e estreitamento dos laços entre Brasil e Japão. Na $1^{\text {a }}$ caravana foram 25 alunos e dois professores como acompanhantes. 
(1)

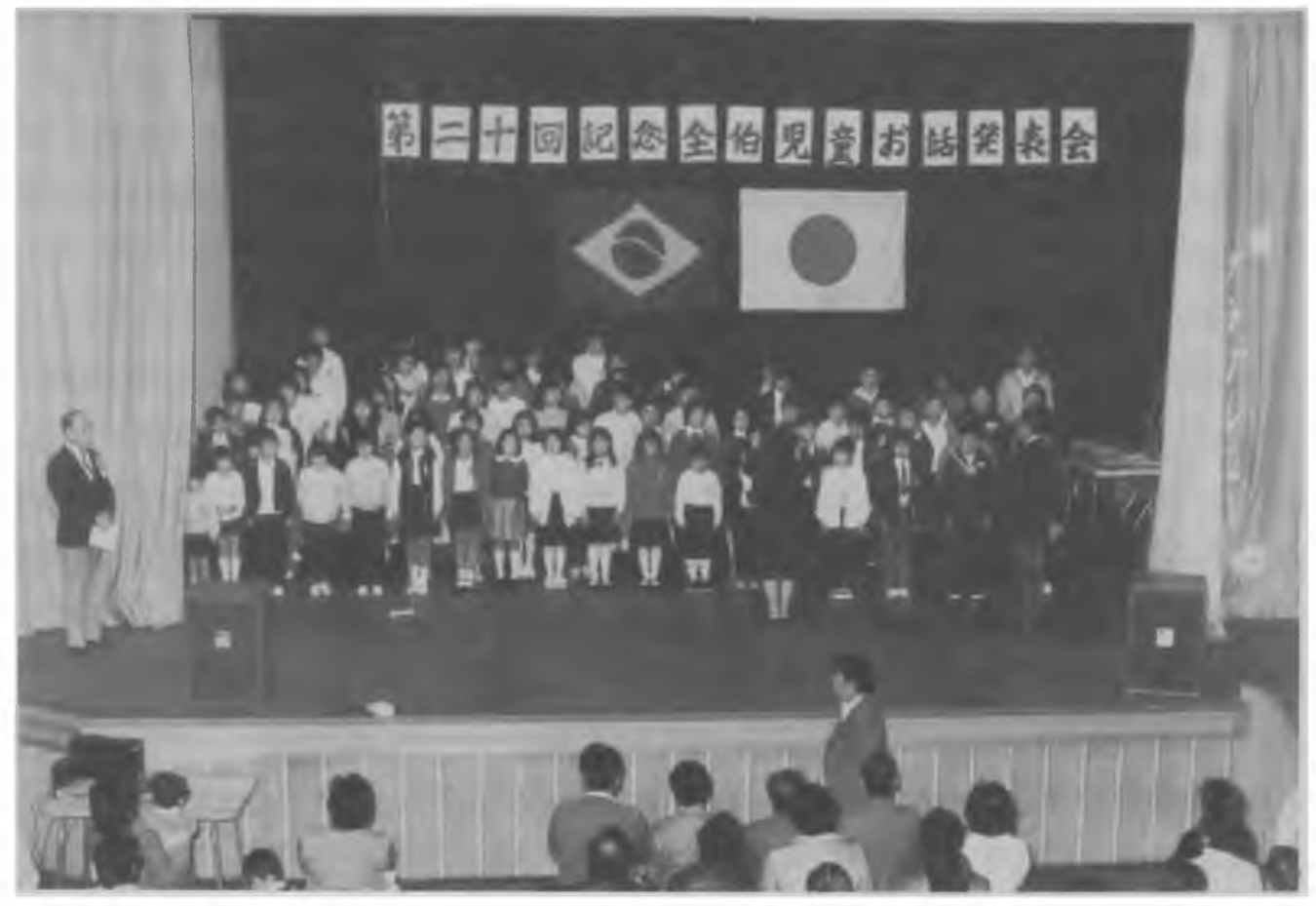

(2)
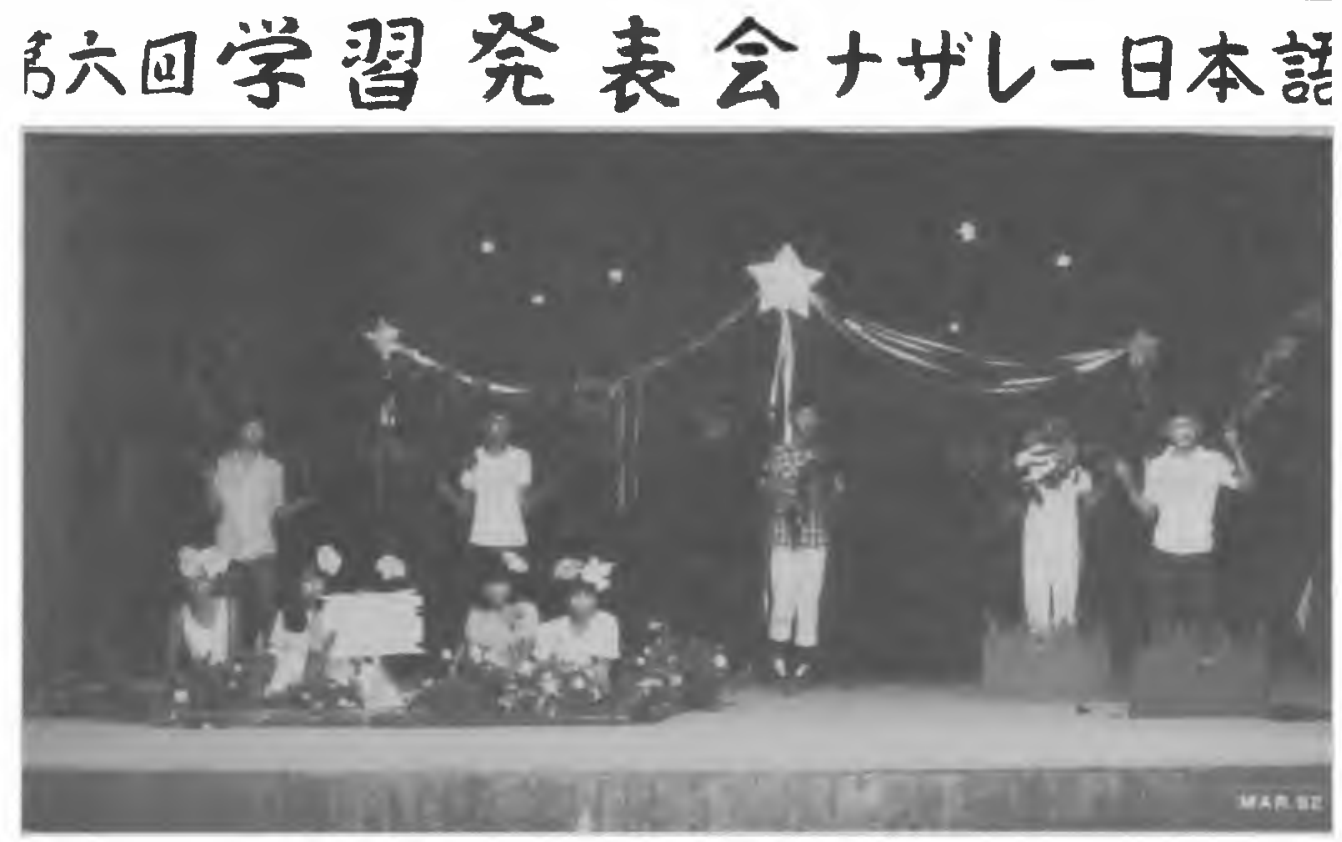

1. $20^{\circ}$ Concurso de Oratória - Ohanashi taikai, Bunkyô, Liberdade, São Paulo, década de 1980.

2. $6^{\mathrm{a}}$ Apresentação das Atividades Escolares - Dai Rokkai Gakushû Hapyôkai, Nazaré, São Paulo, março de 1982.

Arquivo pessoal: Profa. Kumiko Kanematsu 
As escolas comunitárias desse período em nada se assemelham às escolas de idiomas ou mesmo às escolas brasileiras públicas de hoje. Elas eram um espaço social e de convivência para promoção da cultura e da língua japonesa, com todas as aulas ministradas na língua japonesa por professores nativos para crianças bilíngues. Para complementar as atividades escolares, havia ainda Rinkan Gakkô (Viagem de Concentração) e Shûgaku Ryôkô (Viagem Escolar), que eram realizados anualmente com a colaboração de todos os pais, que eram membros da comunidade, além das atividades esportivas que envolviam outras comunidades, tornando-se um acontecimento de caráter inter-comunitário e regional ${ }^{40}$.

É importante esclarecer que as escolas japonesas não eram homogêneas: a dinâmica que conduzia um bom rendimento da escola dependia do empenho e interesse da comunidade, bem como a presença de um professor engajado com o ensino. E com a promoção de atividades humanísticas dirigidas às crianças, as escolas conseguiam integrar os diferentes grupos de faixa etária existentes na comunidade como o Rôjinkai (Associação da Terceira Idade) que eram os principais expectadores. Para a engrenagem funcionar, contavam com a força-tarefa das mães, denominada Fujinkai (Associação das Senhoras) para o preparo das refeições, e a dos jovens Seinenkai (Associação dos Jovens) que se encarregavam da logística e da acomodação do espaço, transporte de mobiliários etc. Os técnicos das atividades esportivas eram membros da comunidade e japoneses nativos o que favorecia o uso da língua como meio de comunicação com as crianças em fase de desenvolvimento linguístico.

Os registros de edições comemorativas de comunidades como as de Araçatuba, Presidente Prudente, Marília, Registro, São Miguel Arcanjo e Pilar do Sul, assim como na Grande São Paulo, onde os japoneses estavam concentrados (Mogi das Cruzes $^{41}$, Suzano ${ }^{42}$ e região do $\mathrm{ABC}$ ) comprovam essa dinâmica de relações existentes não só intracomunitárias como também intercomunitárias. A mesma situação se estende às cidades paranaenses, como Londrina, Assai, Maringá, Marialva, Nova Esperança, onde a população de japoneses era concentrada.

40. As redes de relações entre as comunidades já tinham sido estabelecidas desde o período pré-guerra, no qual as atividades esportivas eram intensamente praticadas. Vide anuário comemorativo de Álvares Machado, por exemplo (início da imigração nesta cidade em 1918).

41. Em Mogi das Cruzes, na década de 1980 a 1990, havia muitos alunos estudando japonês, sendo que somente nessa cidade havia cerca de trinta escolas comunitárias, sem contar as que ficavam situadas nos arredores da cidade

42. Em Suzano, muitas escolas comunitárias ficavam espalhadas também nas zonas rurais, uma vez que a distância ainda continuava sendo um empecilho no transporte das crianças. Só em Fukuhaku (Vila Ipelândia), havia 170 alunos na década de 1980. 


\section{As Escolas Comunitárias e as Escolas Brasileiras}

A partir do pós-guerra, com ingresso cada vez mais frequente dos descendentes em escolas brasileiras e a continuidade de estudos nos níveis mais avançados, uma nova dinâmica se estabeleceu. Houve aumento de construção de pensionatos para filhos de japoneses estudarem nas cidades grandes do interior e também em São Paulo. Já na década de 1960 , os que dispunham de condições financeiras mais favoráveis moravam na zona urbana e trabalhavam na zona rural. Diversos anuários comemorativos expõem a construção do pensionato com orgulho, como também os jornais da comunidade ajudaram na propagação das inaugurações por toda parte.

Em Mogi das Cruzes $^{43}$, na década de 1950 a 1960, líderes de bairros dos arredores da cidade reuniram-se para discutir como seria a construção do pensionato para atender a demanda de alunos ingressantes no ginásio. Cidades do interior paulista, como Araçatuba e Presidente Prudente, também tinham seus pensionatos que abrigavam jovens das regiões próximas, devido às boas ofertas de escolas brasileiras públicas. É nessa esteira que surge o pensionato Harmonia (Harmonia Gakuseiryô) em São Bernardo do Campo, em 1956, que mais tarde foi transformado em escola bilíngue particular, hoje denominado de Colégio Harmonia. Essa fase de envio de filhos aos pensionatos continuará em alta até o final da década de 1990, quando a maioria dos japoneses e descendentes passou a fixar residência em zonas urbanas.

Segundo relato de professores que trabalharam no pensionato, a tarefa diária não consistia apenas no ensino, mas também na preparação das três refeições, passar a roupa, controlar o horário de saída e retorno; a jornada de trabalho era longa, cabendo-lhes ainda tomar conta da sede da associação onde estava instalado o pensionato ${ }^{44}$. Expressões Burajiru-gakkô (escola brasileira) em oposição ao Nihongo-gakkô (escola japonesa) e otoko-sensei (professor-homem) e on na-sensei (professor-mulher) ${ }^{45}$ são denominações que surgiram e ficaram em voga entre 1960 e 1980, abarcando uma realidade nova em formação. Com o aumento de alunos, era comum o professor pedir ajuda à mulher; para distingui-los, as crianças chamavam-nos de otoko-sensei e on na-sensei, e que, pode ser considerado como emprego de interlíngua.

43. Comissão do Cinquentenário da fundação de Mogi das Cruzes. História dos cinquenta anos de Mogi. Editora Cultura Imai Ltda. 1971.

44. Handa (op.cit.:504) descreve a tarefa do dia a dia do casal de japoneses que trabalham num internato, cuja descrição minuciosa deixa transparecer o papel do marido e da esposa em que o ato de ensinar constitui em uma das atividades, diante dos inúmeros afazeres para manter um internato funcionando.

45. Essa denominação ficou particularmente bem conhecida entre as crianças ao se referirem aos professores de escolas comunitárias, que muitas vezes, não eram conhecidos pelos seus nomes e sim por sensei (professor). Sem contar que há um erro de combinação sintagmática das palavras, sendo necessário a interposição de um morfema de caso genitivo, como otoko-no-sensei e on'na-no-sensei respectivamente. 


\section{Considerações Finais}

A retomada das escolas comunitárias foi importante e teve papel significativo para a comunidade japonesa, devido ao interesse remanescente ou renovado de muitos pais no ensino da língua japonesa como língua de herança. No entanto, notaram-se mudanças no perfil da comunidade japonesa no Brasil, impulsionadas pela entrada gradativa de descendentes em escolas brasileiras em níveis cada vez mais avançados. Esse nova demanda foi caracterizada pela construção de pensionatos para atender à mudança dos alunos para centros urbanos com melhores condições de infraestrutura educacional. Ao mesmo tempo em que se incrementaram as atividades das escolas comunitárias, o acesso de descendentes às escolas brasileiras também se acentuava, propiciando um ambiente favorável à manutenção do bilinguismo.

\section{Referências Bibliográficas}

ALIANÇA CULTURAL BRASIL-JAPÃO. Relatório do I Simpósio de Ensino de Língua Japonesa. São Paulo. Relatório, 1979.

ALIANÇA CULTURAL BRASIL-JAPÃO. Denshô e no Michi: Burajiru Shakai ga Yôkyûsuru Nihongo Kyôiku to Sono Tenbô. (O Caminho para a Transmissão: o Ensino de Língua Japonesa que a Sociedade Brasileira Espera e os Seus Desdobramentos). São Paulo. Relatório, 1982.

ASSOCIAÇÃO CULTURAL NIPO BRASILEIRA DE ARAÇATUBA. Araçatuba Bunkyô 50-nenshi. (História dos Cinquenta Anos da Associação Nipo-brasileria de Araçatuba) São Paulo, 1978.

CARDOSO, R. C. L. Estrutura Familiar e Mobilidade Familiar: Estudo dos Japoneses no Estado de São Paulo. São Paulo: Caleidos-Primus Comunicação e Consultoria Integrada S/C Ltda, 1998.

COMISSÃO DO CINQUENTENÁRIO DA FUNDAÇÃO DE MOGI DAS CRUZES. História dos Cinquenta Anos de Mogi. Editora Cultura Imai Ltda. 1971.

DOI, E.T. O Ritmo Bimoraico e as Moras Não-Plenas do Japonês: Reflexões sobre o Ensino da Língua Oral. In: Trabalhos em Linguística Aplicada, n. 36, Unicamp, Campinas, 2000 (p.51-60).

. A Presença Japonesa no Brasil: a Língua Falada pela Comunidade Nipo-Brasileira. Letterature D'America; Revista Trimestrale, Roma, Bulzoni Editore, $n^{\circ}$ 93-94, ano XXII, 2002, p. 19-36.

O Ensino do Japonês como Língua da Imigração. Estudos Linguísticos XXXV, Campinas, pp.66-75, 2006.

. Atitude de Imigrantes Japoneses e Descendentes em Relação ao Japonês Falado nas Comunidades Nikkei. In: Angela B. Kleiman e Marilda C. Cavalcanti (orgs.) Linguística Aplicada: Suas Faces e Interfaces. São Paulo, Mercado de Letras, 2007. 
FONTENELE REIS, Maria Edileuza. Brasileiros no Japão: o Elo Humano das Relações Bilaterais. (Masato Ninomiya org.). 2a .edição. São Paulo: Kaleidus-Primus, 2002.

FUNDAÇÃO JAPÃO (2006). Diretório de Instituições Educacionais de Língua Japonesa do Exterior. <http://www.jpf.go.jp/> Acesso em: 10 nov. 2007.

HANDA, Tomoo. Imin no Seikatsu no Rekishi: Burajiru Nikkeijin ga Ayunda Michi. (História da Vida do Imigrante: o Caminho Percorrido pelos Brasileiros Nikkeis) São Paulo: Centro de Estudos Nipo-Brasileiros, 1970.

ISHIHARA, Tatsuo. Cotia Shôgakkô no Gojûnen (1916-1966): Burajiru Nikkei Jidô Kyôiku no Jissai [Os Cinquenta Anos da Escola Primária de Cotia (1916-1966): a Prática da Educação de Crianças Nipo-Brasileiras]. São Paulo: 1978.

JAPAN INTERNATIONAL COOPERATION AGENCY. Pesquisa sobre a Situação Atual das Escolas Japonesas Voltadas aos Filhos de Imigrantes na América Latina e no Canadá, relatório, 1986.

JIN'NAI S. In: COMISSÃO DA HISTÓRIA DOS 70 ANOS DE IMIGRAÇÃO JAPONESA NO BRASIL (org.) História dos 70 Anos de Imigração Japonesa no Brasil. São Paulo: 1981.

KUNO, Mariko. Nikkei Burajirujin no Nihongo: Nikkei Issei no Nihongo Jijô. In: Kokugakuin Zasshi, vol. 108, n. 11, Tokyo, 2007.

KUYAMA, M. Fatores Sociais e Frequência de Empréstimos do Português no Japonês Falado pelos Imigrantes no Brasil - o Caso do Distrito Federal. In: Revista Estudos Japoneses, $n^{\circ} 20$, CEJ / USP, 2000, p. 69-85.

O Uso da Língua Japonesa na Comunidade Nipo-Brasileira: o Empréstimo Lexical no Japonês Falado pelos Imigrantes - caso de Distrito Federal. 1999. Dissertação de mestrado. Universidade de São Paulo, são Paulo, 1999.

MORALES, L. M. Cem Anos de Imigração Japonesa no Brasil: o Ensino de Japonês como Língua Estrangeira. Tese de doutoramento. Departamento de Linguística, Faculdade de Filosofia, Letras e Ciências Humanas. Universidade de São Paulo, 2009-a.

MORIWAKI, R. Nihongo Kyôiku no Hensen (A Transição da Filosofia Norteadora do Ensino de Língua Japonesa $-1^{\mathbf{a}}$ parte). In: Revista $\mathbf{n}^{\mathbf{0}}$ 2, Centro de Estudos Nipo-Brasileiros, 1998, p. 71-85.

MORIWAKI, R. Nihongo Kyôiku no Hensen II (A Transição da Filosofia Norteadora do Ensino de Língua Japonesa - $2^{\mathbf{a}}$ parte). In: Revista $\mathbf{n}^{\mathbf{0}} \mathbf{4}$, Centro de Estudos Nipo-Brasileiros, 1999 , p. 43-75.

NICHIGAKUREN (org.). Ikusanga - Zenpaku Nichigo Kyôikushi (História do Ensino de Japonês no Brasil). São Paulo, 1966.

NICHIGAKUREN (org.) Relatório da Primeira Exposição de Crianças Brasileiras e Viagem de Intercambio dos Jovens ao Japão. Nippakujôhôsha, 1981.

NIWA, Y. O Ensino de Língua Japonesa no Brasil. In: Imigração Japonesa no Brasil - Meio Século após a II Guerra Mundial (1953-2003), Editora Toppan Press, 2004, p. 168-170.

NOMOTO, K. Burajiru no Nihongo Kyôiku. Nihongo Kyôiku, Tokyo, no 24, p. 415-20, agosto, 1974. 
SAITO, H. (org.). A Presença Japonesa no Brasil. São Paulo: EDUSP, 1980.

SHIBATA, Hiromi. As Escolas Japonesas Paulistas (1915-1945): a Afirmação de uma Identidade Étnica. 1997. Dissertação de Mestrado. Faculdade de Educação da Universidade de São Paulo, São Paulo, 1997.

SOCIEDADE DE DIFUSÃO DA CULTURA NIPO-BRASILEIRA. Pesquisa sobre a Situação Atual das Instituições de Difusão do Ensino no Brasil, 1977.

TAKANO,Y. Tensão Diglóssica na Aquisição de Língua: um Estudo de Bilíngues NipoBrasileiros. 2002. Dissertação de Mestrado. Universidade de Brasília, Brasília, 2002.

WAKISAKA, K. et alii. Oitenta Anos de História da Imigração Japonesa no Brasil. Editora Toppan Pres, 1996. 